\title{
BMJ Open In-hospital mortality of cardiogenic shock complicating ST-elevation myocardial infarction in Malaysia: a retrospective analysis of the Malaysian National Cardiovascular Database (NCVD) registry
}

\author{
Padmaa Venkatason, ${ }^{1}$ Yong Z Zubairi, ${ }^{2}$ Wan Azman Wan Ahmad, ${ }^{1}$ \\ Muhammad Imran Hafidz, ${ }^{1}$ Muhammad Dzafir Ismail, ${ }^{\oplus 1}$ Mohd Firdaus Hadi, ${ }^{1}$ \\ Ahmad Syadi Mahmood Zuhdi ${ }^{1}$
}

To cite: Venkatason $P$ Zubairi YZ, Wan Ahmad WA, et al. In-hospital mortality of cardiogenic shock complicating ST-elevation myocardial infarction in Malaysia: a retrospective analysis of the Malaysian National Cardiovascular Database (NCVD) registry. BMJ Open 2019;9:e025734. doi:10.1136/ bmjopen-2018-025734

- Prepublication history for this paper is available online. To view these files, please visit the journal online (http://dx.doi. org/10.1136/bmjopen-2018025734).

Received 7 August 2018 Revised 11 January 2019 Accepted 8 March 2019

Check for updates

(c) Author(s) (or their employer(s)) 2019. Re-use permitted under CC BY-NC. No commercial re-use. See rights and permissions. Published by BMJ.

${ }^{1}$ Department of Medicine, University of Malaya Medical Centre, Kuala Lumpur, Malaysia

${ }^{2}$ Foundation Studies in Science, University of Malaya, Kuala Lumpur, Malaysia

Correspondence to Dr Ahmad Syadi

Mahmood Zuhdi;

syadizuhdi@yahoo.co.uk

\section{ABSTRACT}

Objectives Cardiogenic shock (CS) complicating ST-elevation myocardial infarction (STEMI) carries an extremely high mortality. The clinical pattern of this life threatening complication has never been described in Malaysian setting. This study is to investigate the incidence, clinical characteristics and outcome of STEMI patients with CS in our population.

Design A retrospective analysis of STEMI patients from 18 hospitals across Malaysia contributing to the Malaysian National Cardiovascular Database-acute coronary syndrome) registry (NCVD-ACS) year 2006-2013.

Participants 16517 patients diagnosed of STEMI from 18 hospitals in Malaysia from the year 2006 to 2013.

Primary outcome measures In-hospital and 30 day postdischarge mortality.

Results CS complicates $10.6 \%$ of all STEMls in this study. They had unfavourable premorbid conditions and poor outcomes. The in-hospital mortality rate was $34.1 \%$ which translates into a 7.14 times mortality risk increment compared with STEMI without CS. Intravenous thrombolysis remained as the main urgent reperfusion modality. Percutaneous coronary interventions (PCI) in CS conferred a $40 \%$ risk reduction over non-invasive therapy but were only done in $33.6 \%$ of cases. Age over 65 , diabetes mellitus, hypertension, chronic lung and kidney disease conferred higher risk of mortality.

Conclusion Mortality rates of CS complicating STEMI in Malaysia are high. In-hospital PCI confers a 40\% mortality risk reduction but the rate of $\mathrm{PCl}$ among our patients with CS complicating STEMI is still low. Efforts are being made to increase access to invasive therapy for these patients.

\section{INTRODUCTION}

Cardiogenic shock (CS) is an important cause of death in acute ST-elevation myocardial infarction (STEMI). ${ }^{1-3}$ Left ventricular dysfunction is the most common underlying
Strengths and limitations of this study

- To our knowledge, this is the first study to describe the outcome of cardiogenic shock complicating STEMI in Malaysia.

- The analysis was done on a large data consisting 16517 patients from 18 hospitals across Malaysia. Hence, it is so far the most representative of Malaysian population in general.

- Patients were from multi-racial background representing the major racial groups in Asia, that is, Chinese, Indian and Malay.

- Confounding factors and inter-centre variations in terms of treatment and outcome from this retrospective study cannot be eliminated.

- This study focuses on in-hospital mortality only. The long-term outcome was not analysed due to insufficient follow-up data.

aetiology in CS accounting for about $74.5 \%$ of cases. ${ }^{4}$ There is correlation with the severity of coronary artery disease whereby CS is strongly associated with triple vessel or left main stem coronary involvement ${ }^{6}$

Despite the advancement in reperfusion therapy with invasive percutaneous coronary intervention (PCI), the mortality rate remains high. The in-hospital mortality rate even after successful PCI is reported to be as high as $40 \% \cdot{ }^{7-9}$ Although the incidence of CS complicating myocardial infarctions (MIs) is only around $4 \%-10 \%,{ }^{10}$ it remains a big challenge in terms of clinical management.

Due to various limitations locally, the rate of coronary reperfusion with primary PCI in STEMI is only about $7 \%$ in Malaysia. ${ }^{11}$ Given the restriction in delivering the preferred 
revascularisation therapy (primary PCI), the outcome of CS complicating MIs in our population has yet been fully described and no comparison ever made with other studies. Hence, we use data from the Malaysian National Cardiovascular Database-acute coronary syndrome 20062013 (NCVD-ACS 2006-2013) to investigate the characteristics and outcome of CS complicating STEMIs in Malaysia.

\section{METHODS \\ Patient population}

A total of 16517 patients diagnosed with STEMI were identified from the Malaysian NCVD-ACS from year 2006 to 2013. The NCVD is a national registry involving 18 hospitals nationally. It captures clinical data on all patients admitted with acute coronary syndromes. The Ministry of Health Malaysia and the National Heart Association of Malaysia (NHAM) sponsor the registry. Data are collected on admission and throughout the patient stay using a standardised case reporting form. A unique national identification number is given to each patient to avoid duplication. Parameters recorded include baseline characteristics and clinical presentation, in-hospital treatment, procedural details and clinical outcome.

STEMI is defined as a persistent ST-segment elevation of $\geq 1 \mathrm{~mm}$ in two contiguous electrocardiographic leads or the presence of a new left bundle branch block in the setting of positive cardiac markers and/or typical cardiac pain. Patients were divided into two groups based on their Killip class on presentation. Those in Killip class IV were grouped under 'CS' ( $\mathrm{n}=1753)$ while those in Killip classes I, II and III were grouped under 'non-CS' ( $\mathrm{n}=14764)$. The two groups were compared in terms of clinical characteristics, in-hospital invasive treatment, pharmacotherapy and all cause in-hospital mortality. A cross-check with the national death registry was also done to verify the patients' mortality status.

The results of the study will be made public in NHAM website through the NCVD annual reports in interest for the view of the participants. In this study, we use retrospective cohort studies looking at data that have already been existing.

\section{Definition of Killip class}

Killip class IV is defined as the presence of hypotension with a systolic blood pressure (BP) lower than $90 \mathrm{~mm} \mathrm{Hg}$ and evidence of peripheral vasoconstriction. Below are the definitions of the other Killip classes:

Killip I: No clinical signs of heart failure.

Killip II: Presence of rales or crepitation in the lungs bases only or a third heart sound (S3).

Killip III: Presence of frank acute pulmonary oedema.

Killip IV: CS or hypotension (measured as systolic BP $<90 \mathrm{~mm} \mathrm{Hg}$ ), and evidence of peripheral vasoconstriction.

\section{Statictical analysis}

Categorical variables were described as numbers and percentages. The differences were analysed by $\chi^{2}$ test or Fisher exact test. Continuous variables were expressed as median and differences were analysed using t-test. To avert biases in the estimates and loss of power, missing data for explanatory variables were assumed to be missing at random. A generalised linear model with a log link, binomial distribution and a robust variance estimator was used to estimate the risk ratios. The risk ratios represent the relative risk for mortality of the non-CS group compared with the CS group. Subsequently, risk ratios of CS patients with PCI done and without PCI were also compared. Variables that were statistically significantly different (a two-sided $\mathrm{p}$ value of less than 0.05 ) between the CS and non-CS patients, that were of clinical importance, and that had sufficient outcomes in the respective subcategories were adjusted for. Finally, binary logistics regression was executed to determine the independent predictors of in-hospital mortality among CS patients.

\begin{tabular}{|c|c|c|c|}
\hline & $\begin{array}{l}\text { CS (Killip IV) } \\
(\mathrm{n}=1753)\end{array}$ & $\begin{array}{l}\text { Non-CS (Killip I- } \\
\text { III) }(n=14764)\end{array}$ & $P$ value \\
\hline \multicolumn{4}{|l|}{ Age } \\
\hline 64 years or less & $1214(71.4 \%)$ & $11141(77.4 \%)$ & $<0.001$ \\
\hline$>65$ years & $486(28.6 \%)$ & 3252 (22.6\%) & \\
\hline \multicolumn{4}{|l|}{ Gender } \\
\hline Male & 1455 (83.0\%) & 12687 (85.9\%) & 0.001 \\
\hline Female & $298(17.0 \%)$ & 2077 (14.1\%) & \\
\hline \multicolumn{4}{|l|}{ Ethnicity } \\
\hline Malay & $1113(63.5 \%)$ & $8631(58.5 \%)$ & 0.001 \\
\hline Chinese & $285(16.3 \%)$ & $2632(17.8 \%)$ & \\
\hline Indian & $247(14.1 \%)$ & $2466(16.7 \%)$ & \\
\hline Others & $108(6.2 \%)$ & $1035(7.0 \%)$ & \\
\hline \multicolumn{4}{|l|}{ Risk factors } \\
\hline Smoking (active/ex) & $1109(67.4 \%)$ & $10020(70.0 \%)$ & 0.028 \\
\hline Diabetes & $732(51.3 \%)$ & $5257(42.3 \%)$ & $<0.001$ \\
\hline Hypertension & $891(61.3 \%)$ & $7270(57.2 \%)$ & 0.002 \\
\hline Hyperlipidaemia & $372(32.1 \%)$ & $3754(35.3 \%)$ & 0.030 \\
\hline Family history & $158(9.0 \%)$ & $1658(11.2 \%)$ & $<0.001$ \\
\hline \multicolumn{4}{|l|}{ Premorbids } \\
\hline Cerebrovascular & $49(3.4 \%)$ & $386(3.1 \%)$ & 0.422 \\
\hline Previous MI & $208(15.1 \%)$ & $1553(12.6 \%)$ & 0.009 \\
\hline Peripheral vascular disease & $10(0.7 \%)$ & $35(0.3 \%)$ & 0.007 \\
\hline Chronic kidney disease & $100(7.1 \%)$ & $461(3.7 \%)$ & $<0.001$ \\
\hline Chronic lung disease & $58(4.1 \%)$ & $285(2.3 \%)$ & $<0.001$ \\
\hline \multicolumn{4}{|l|}{ Myocardial infarct type } \\
\hline Inferior infarct & $732(41.8 \%)$ & $5310(36.0 \%)$ & $<0.001$ \\
\hline Anterior infarct & $743(42.4 \%)$ & $6772(45.9 \%)$ & 0.001 \\
\hline LVEF mean \pm SD & $38.7 \pm 12.2$ & $46.1 \pm 11.1$ & 0.025 \\
\hline
\end{tabular}

CS, cardiogenic shock; LVEF, left ventricular ejection fraction; MI, myocardial infarction; non-CS, non-cardiogenic shock. 
Table 2 Coronary reperfusion and revascularisation therapy in STEMI patients who have CS and do not have CS

\begin{tabular}{|c|c|c|c|}
\hline & CS STEMI & Non-CS STEMI & P value \\
\hline \multicolumn{4}{|l|}{ Thrombolysis } \\
\hline Given & $1216(71.4 \%)$ & $10885(75.2 \%)$ & $<0.001$ \\
\hline Not given-missed & $129(7.6 \%)$ & $1690(11.7 \%)$ & \\
\hline Not given-patient refusal & $4(0.2 \%)$ & $49(0.3 \%)$ & \\
\hline In-hospital $\mathrm{PCl}^{*}$ & $537(33.6 \%)$ & $4083(29.5 \%)$ & 0.001 \\
\hline Door to needle time for thrombolysis (min) & 45.0 & 60.0 & $<0.001$ \\
\hline Symptom to door time (min) & $249.98+/-224.74$ & $239.34+/-215.37$ & 0.074 \\
\hline
\end{tabular}

${ }^{*} \mathrm{PCl}$ done during index admission that was not primary angioplasty-includes rescue $\mathrm{PCl}$, pharmacoinvasive $\mathrm{PCl}$ and early routine $\mathrm{PCl}$.

CS, cardiogenic shock; PCI, percutaneous coronary intervention; STEMI, ST-elevation myocardial infarction.

All analyses were conducted using SPSS V.21 statistical software.

\section{Patient and public involvement}

There is no patient or public involvement in the development of this study's research question and outcome. All data were obtained retrospectively from the Malaysian NCVD-ACS.

\section{RESULTS}

Table 1 illustrates the comparison in baseline characteristics between the CS and non-CS group. A total of 1753 out of 16517 patients (10.6\%) presented with CS. Demographically, the CS group contained more patients over the age of $65(28.6 \%$ vs $22.6 \% \mathrm{p}<0.001)$. Females and Malay ethnic groups were also seen to be significantly more prevalent in the CS group. In terms of cardiovascular risk factors, they had higher rate of diabetes and hypertension but unexpectedly lower rate of smoking, hyperlipidaemia and premature family history. Other related premorbid conditions were unfavourable to the CS group where they had higher rate of previous MI, cerebrovascular, peripheral vascular, chronic kidney and chronic lung diseases.

\begin{tabular}{llrl}
\hline Table 3 & In-hospital pharmacotherapy & \\
\hline Medications & $\begin{array}{l}\text { CS STEMI } \\
(\mathbf{n}=\mathbf{1 7 5 3})\end{array}$ & $\begin{array}{l}\text { Non-CS STEMI } \\
(\mathbf{n}=\mathbf{1 4 7 6 4})\end{array}$ & P value \\
\hline Aspirin & $1024(75.7 \%)$ & $12470(93.3 \%)$ & $<0.001$ \\
ADP-antagonist & $632(67.8 \%)$ & $8346(81.4 \%)$ & $<0.001$ \\
ACE-I/ARB & $529(30.3 \%)$ & $8128(55.8 \%)$ & $<0.001$ \\
Beta blocker & $659(51.1 \%)$ & $9185(71.5 \%)$ & $<0.001$ \\
Statin & $957(70.9 \%)$ & $12024(90.5 \%)$ & $<0.001$ \\
\hline
\end{tabular}

ACE-I, ACE converting enzyme inhibitor; ADP, ADP diphosphate; ARB, angiotensin receptor blocker; CS, cardiogenic shock; STEMI, ST-elevation myocardial infarction.
Table 2 compares the revascularisation treatment between the two groups. Intravenous thrombolysis remained the main emergency reperfusion therapy for both CS and non-CS patients. Although there was no significant difference of symptom to door times between the two groups, the door to needle time was significantly shorter for CS patients $(45 \mathrm{~min}$ vs $60 \mathrm{~min} \mathrm{p}<0.001$ ). The difference in the rate of primary PCIs between the two groups was small (11.7\% CS vs $10.0 \%$ non-CS). Total rate of in-hospital PCIs (inclusive of primary PCIs) was however significantly higher in CS patients $(33.6 \%$ vs $29.5 \% \mathrm{p}=0.001$ ). Table 3 shows the administrative rate of evidence-based pharmacotherapy during the admission, which favoured the non-CS patients across all class of medications especially antihypertensives.

Table 4 compares the all cause in-hospital mortality rate between patients with CS and non-CS. The mortality rate was different between the two groups $(34.1 \%$ CS vs $5.6 \%$ non-CS, p value $<0.001)$ After multivariate adjustment of confounding factors, we found that the CS group had 7.14 times higher mortality risk compared with the non-CS group.

Mortality data were obtained from official records from the National Registration Department of Malaysia and cross-referenced to patients, however we were unable to get information for 29 patients $(0.017 \%)$ in the CS group for undetermined reasons. Table 5 shows the sub-analyses of in-hospital mortality rates among CS patients. Those who had PCI done during the admission had a lower rate of in-hospital mortality (27.0\% vs $38.9 \%$ ) compared with those who did not. Adjusted mortality risk ratio showed that there was a $40 \%$ mortality risk reduction in those with PCI done.

Table 6 shows univariate analysis of clinical variables related to mortality in the CS group. All variables that were statistically significant from this table were then grouped into a multivariate logistic regression to determine the independent predictors of in-hospital mortality within the CS group. The result of the multivariate logistic regression is tabulated in Table 7 . We found that the presence of 
Table 4 In-hospital and 30 day mortality rates

\begin{tabular}{lcclll}
\hline & No of patients & Death (\%) & Unadjusted risk ratio & Adjusted risk ratio & P value \\
\hline In-hospital mortality & & & & & \\
CS & 1753 & $598(34.1)$ & $6.827(6.104,7.954)$ & $7.143(6.365,8.017)$ & $<0.001$ \\
Non-CS & 14764 & $821(5.6)$ & 1 & 1 & \\
30-Day mortality & & & & & $<0.001$ \\
CS & 1753 & $634(36.2)$ & $7.587(7.002,9.552)$ & $8.863(7.848,10.009)$ & \\
\hline Non-CS & 14764 & $1085(7.3)$ & 1 & 1 & \\
\hline
\end{tabular}

CS, cardiogenic shock.

\begin{tabular}{|c|c|c|c|c|c|}
\hline In-hospital mortality & No of patients & Death (\%) & Unadjusted risk ratio & Adjusted risk ratio & $P$ value \\
\hline $\mathrm{PCl}$ done & 537 & $145(27)$ & $0.535(0.428,0.670)$ & $0.600(0.513,0.700)$ & $<0.001$ \\
\hline $\mathrm{PCl}$ not done & 1063 & $414(38.9)$ & 1 & 1 & \\
\hline
\end{tabular}

$\mathrm{PCl}$, percutaneous coronary intervention.

hypertension, diabetes mellitus, chronic lung and kidney diseases, and age of over 65 carried statistically significantly higher mortality risks and hence they seem to be independent predictors of in-hospital mortality. Table 8 shows the length of stay between the two groups. Patients with CS have significantly longer duration of inpatient stay compared with non-CS.

\section{DISCUSSION}

CS is a clinical state where cardiac dysfunction results in inadequate tissue perfusion. CS is characterised by a state of haemodynamic insufficiency that may involve hypotension (systolic blood pressure $<90 \mathrm{~mm} \mathrm{Hg}$ ), significant decrease in mean arterial pressure from baseline and

Table 6 Comparison of clinical factors between survivors and non-survivors of cardiogenic shock

\begin{tabular}{lrlr}
\hline & $\begin{array}{l}\text { Survivors } \\
(\mathbf{n}=1126)\end{array}$ & $\begin{array}{l}\text { Non-survivors } \\
(\mathbf{n}=598)\end{array}$ & P value \\
\hline Age $>65$ years & $226(20.8 \%)$ & $253(43.1 \%)$ & $<0.001$ \\
\hline Diabetes & $429(47.5 \%)$ & $295(58.2 \%)$ & $<0.001$ \\
\hline Hypertension & $520(56.5 \%)$ & $361(70.4 \%)$ & $<0.001$ \\
\hline Smoking status & & & \\
\hline \multicolumn{1}{|c|}{ Active/ex-smokers } & $607(67.0 \%)$ & $219(48.6 \%)$ & $<0.001$ \\
\hline Non-smokers & $299(33.0 \%)$ & $232(51.4 \%)$ & \\
\hline Dyslipidaemia & $224(30.3 \%)$ & $143(35.3 \%)$ & 0.083 \\
\hline Previous Ml & $126(14.0 \%)$ & $82(17.8 \%)$ & 0.061 \\
\hline Chronic lung disease & $25(2.7 \%)$ & $32(6.6 \%)$ & 0.001 \\
\hline Cerebrovascular disease & $27(2.9 \%)$ & $21(4.4 \%)$ & 0.161 \\
\hline Peripheral vascular disease & $8(0.9 \%)$ & $2(0.4 \%)$ & 0.337 \\
\hline Chronic renal disease & $46(5.0 \%)$ & $54(11.2 \%)$ & $<0.001$ \\
\hline
\end{tabular}

MI, myocardial infarction. reduced cardiac index. CS can be multifactorial but most commonly occurs secondary to MI.

CS complicating an MI more commonly occurs in ST elevation myocardial infarctions (STEMIs) compared with non-STEMIs and is a predictor of poor prognosis. Data from our NCVD registry showed in-hospital mortality rates of $34.1 \%$. This figure is lower than other MI registries and trials such as the SHOCK trial, which reported in hospital mortality rates of at least $48 \%$. Reasons for the lower figures are unclear, but may be contributed to by a common practice of early hospital discharging of STEMI patients, which may not capture data on patients who

Table 7 Logistic regression of predictors for in-hospital mortality in cardiogenic shock

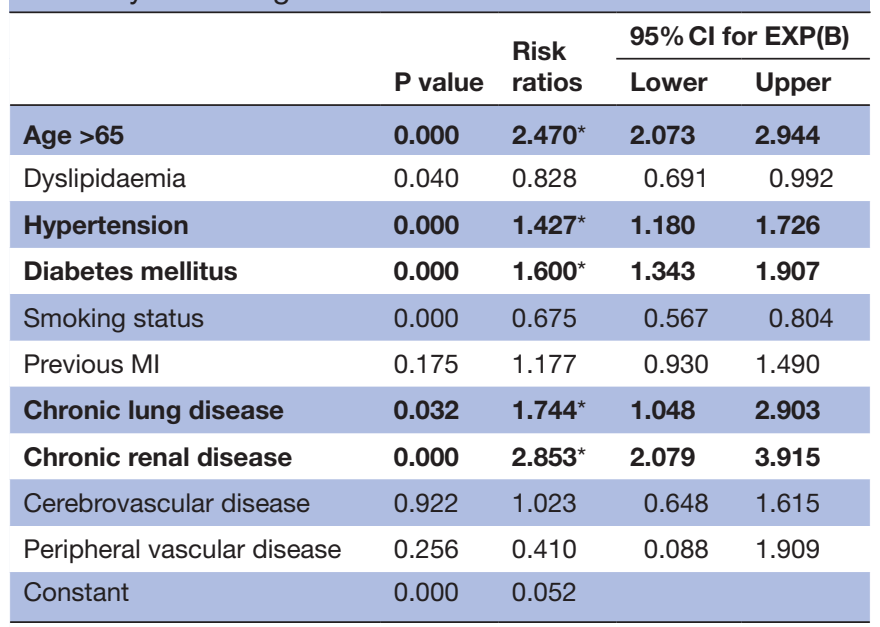

The bold fonts indicate the variables that predict in hospital mortality in cardiogenic shock patients.

*Statistically significant predictors of mortality.

$\mathrm{MI}$, myocardial infarction. 
Table 8 Length of stay of cardiogenic shock (CS) versus non-CS patients

\begin{tabular}{llll}
\hline Total day stay & $\begin{array}{l}\text { Cardiogenic } \\
\text { shock }\end{array}$ & $\begin{array}{l}\text { Non-cardiogenic } \\
\text { shock }\end{array}$ & P value \\
\hline Mean & $8.17(7.53,8.82)$ & $5.21(5.12,5.29)$ & 0.014 \\
SD & 11.561 & 5.102 & \\
\hline
\end{tabular}

died at home early after discharge that would be reflected in 30-day outcomes if these data were available.

Preexisting conditions including hypertension, diabetes mellitus, chronic kidney and lung disease conferred a higher risk of death in our patients, which may reflect poor pre-hospital reserve that is ill prepared to cope with a major stressor such as CS. Increasing age was also a predictor of mortality in our cohort with adults over 65 years of age more than twice more likely to die in hospital if they had CS complicating a STEMI. Age was also found in another study to be the parameter most strongly associated with developing CS after an MI with every 10-year increase in age the risk of developing shock was greater by $47 \% .{ }^{12}$ We observed an interesting finding of significantly lower rates of smoking, family history and dyslipidaemia in the CS group. It is not clear whether this represents under-reporting or under-diagnosis of risk factors or these are paradoxical risk factors for developing CS in STEMI in our population. Nonetheless, further studies would be appropriate to investigate this further, perhaps with future data from NCVD.

Data show that CS patients in the setting of acute MI who were treated non-invasively had poorer outcome and primary PCI is superior to thrombolytic therapy. ${ }^{12-16}$ Similar to other registries and studies, our data showed improved survival for patients who underwent in-hospital PCI including primary PCI. ${ }^{12}$ The adjusted risk of death was reduced by $40 \%$ for patients who received PCI during the index admission compared with those who did not. Intravenous thrombolysis remains the most frequent mode of achieving reperfusion in Malaysia due to several factors. PCI in Malaysia is more costly than thrombolysis and primary or urgent PCI services are limited to patients presenting to one of several PCI centres or their network hospitals, which explains why around only $10 \%$ of patients received primary PCI. Nonetheless, in the SHOCK trial, thrombolysis was superior to medical therapy only and is recommended in many guidelines as a reperfusion strategy when PCI is not possible or delayed, particularly when patients present within 3 hours of symptoms. ${ }^{17} \mathrm{We}$ did not have any data on intra-aortic balloon pump or assist devices in our patients in this registry. Our data showed a shorter door to needle time in patients presenting with CS compared with non-CS. We postulate several factorsCS patients would be appear more ill during initial assessment and the presence of hypotension would likely push for more urgent and swift diagnostic and management steps. In our personal experience, patients with non-CS STEMI may also present in atypical ways that may delay or make assessment less urgent, hence explain the longer door to needle time. Ideally, we would have included the door to balloon data for comparison, however that data are contained in a separate registry called the NCVD-PCI registry, which we did not have access to.

Efforts are being made to increase coverage of primary PCI through the development of a hub and spoke model for STEMI s called the MySTEMI Network. Non-PCI centres (hub) are paired with a PCI capable centre (spoke) whereby patients presenting to a non-PCI hospital with a STEMI are transferred to a PCI centre for primary PCI. ${ }^{18}$ We hope that with the rolling out of this MySTEMI Network nationally, we are able to offer PCI as the main reperfusion modality for STEMI patients. Efforts are also being made to improve prescribing rates of evidencebased therapy through clinical audits and CME sessions. There was a low rate of antiplatelet prescription particularly in the CS group, which has been noted in other local studies. ${ }^{11}{ }^{19}$ Although the exact reasons to explain the low prescription rates in our population were not detailed in the NCVD registry, one factor could be the increased bleeding rates in patients with CS. ${ }^{20}$ We recognise that although our findings are based on the NCVD data, these may not be truly representative of the current situation. The current NCVD is incomplete as there are still several hospitals that are not yet fully contributing towards NCVD data; efforts are however being taken to improve this. Increased reporting will only improve the accuracy of future studies and allow better allocation of resources in improving outcomes.

\section{CONCLUSION}

CS complicated STEMI in about $10.6 \%$ of our patients. The in-hospital mortality was high $(34.1 \%)$ and invasive coronary revascularisation lowered the mortality rate substantially. Similar to other studies, multiple comorbidities including increased age were predictors of poor prognosis. Greater effort is needed to improve outcomes and increased effort is being made to improve the rate of primary and in-hospital PCI.

Acknowledgements We would like to thank all the medical and non-medical personnel involved in the data collection and analysis of the National Cardiovascular Disease-acute coronary syndrome (NCVD-ACS) registry. We also would like to convey our gratitude to the patients' advisers.

Contributors Original idea of the study originated from ASMZ. PV, YZZ and ASMZ designed the study. WAWA, MIH, MFH and MDI wrote the initial draft of the manuscript. PV, MIH, MFH, YZZ, WAWA and MDI analysed the data and revised the manuscript. All authors interpreted the data analysis and scrutinised the final manuscript.

Funding The authors have not declared a specific grant for this research from any funding agency in the public, commercial or not-for-profit sectors.

Competing interests None declared.

Patient consent for publication Not required.

Ethics approval The NCVD registry study was approved by the Medical Review \& Ethics Committee (MREC), Ministry Of Health (MOH) Malaysia in 2007 (Approval Code: NMRR-07-20-250). MREC waived informed consent for NCVD.

Provenance and peer review Not commissioned; externally peer reviewed. 
Data sharing statement No data are available.

Open access This is an open access article distributed in accordance with the Creative Commons Attribution Non Commercial (CC BY-NC 4.0) license, which permits others to distribute, remix, adapt, build upon this work non-commercially, and license their derivative works on different terms, provided the original work is properly cited, appropriate credit is given, any changes made indicated, and the use is non-commercial. See: http://creativecommons.org/licenses/by-nc/4.0/.

\section{REFERENCES}

1. Awad HH, Anderson FA, Gore JM, et al. Cardiogenic shock complicating acute coronary syndromes: insights from the Global Registry of Acute Coronary Events. Am Heart J 2012;163:963-71.

2. Menon V, Hochman JS. Management of cardiogenic shock complicating acute myocardial infarction. Heart 2002;88:531-7.

3. Goldberg RJ, Samad NA, Yarzebski J, et al. Temporal trends in cardiogenic shock complicating acute myocardial infarction. $N$ Engl J Med 1999;340:1162-8.

4. Hochman JS, Boland J, Sleeper LA, et al. Current spectrum of cardiogenic shock and effect of early revascularization on mortality. Results of an International Registry. SHOCK Registry Investigators. Circulation 1995;91:873-81.

5. Hochman JS, Buller CE, Sleeper LA, et al. Cardiogenic shock complicating acute myocardial infarction-etiologies, management and outcome: a report from the SHOCK Trial Registry. J Am Coll Cardiol 2000;36:1063-70.

6. Sanborn TA, Sleeper LA, Webb JG, et al. Correlates of one-year survival inpatients with cardiogenic shock complicating acute myocardial infarction: angiographic findings from the SHOCK trial. $J$ Am Coll Cardiol 2003;42:1373-9.

7. Holmes DR, Berger PB, Hochman JS, et al. Cardiogenic shock in patients with acute ischemic syndromes with and without STsegment elevation. Circulation 1999;100:2067-73.

8. Urban P, Stauffer JC, Bleed D, et al. A randomized evaluation of early revascularization to treat shock complicating acute myocardial infarction. The (Swiss) Multicenter Trial of Angioplasty for Shock-(S) MASH. Eur Heart J 1999;20:1030-8.

9. Stauffer JC, Urban P, Bleed D, et al. Result of the "Swiss" multicenter evaluation of early angioplasty for shock following myocardial infarction. Circulation 1997;96(Suppl 1):I-209.

10. Braunwald EB. Hemodynamic disturbances in acute myocardial infarction. In: Brainwald EB, ed. Heart disease. Philadelphia: W.B. Saunders, 1997:1233-45.

11. Zuhdi AS, Ahmad WA, Zaki RA, et al. Acute coronary syndrome in the elderly: the Malaysian National Cardiovascular Disease DatabaseAcute Coronary Syndrome registry. Singapore Med J 2016;57:191-7.

12. Hasdai D, Califf RM, Thompson TD, et al. Predictors of cardiogenic shock after thrombolytic therapy for acute myocardial infarction. $J$ Am Coll Cardiol 2000;35:136-43.

13. Lindholm MG, Køber L, Boesgaard S, et al. Cardiogenic shock complicating acute myocardial infarction; prognostic impact of early and late shock development. Eur Heart J 2003;24:258-65.

14. Chou TM, Amidon TM, Ports TA, et al. Cardiogenic shock: thrombolysis or angioplasty? J Intensive Care Med 1996;11:37-48.

15. Bates ER, Topol EJ. Limitations of thrombolytic therapy for acute myocardial infarction complicated by congestive heart failure and cardiogenic shock. J Am Coll Cardiol 1991;18:1077-84.

16. Hochman JS, Sleeper LA, Webb JG, et al. Early Revascularization in Acute Myocardial Infarction Complicated by Cardiogenic Shock. N Engl J Med Overseas Ed 1999;341:625-34.

17. French JK, Feldman HA, Assmann SF, et al. Influence of thrombolytic therapy, with or without intra-aortic balloon counterpulsation, on 12-month survival in the SHOCK trial. Am Heart J 2003;146:804-10.

18. Malaysian Heart [Online]. Available: https://www.malaysianheart.org (accessed 9 Feb 2017).

19. Lu HT, Nordin RB. Ethnic differences in the occurrence of acute coronary syndrome: results of the Malaysian National Cardiovascular Disease (NCVD) Database Registry (March 2006 - February 2010). BMC Cardiovasc Disord 2013;13:97.

20. Gilchrist IC, Rao SV. Improving outcomes in patients with cardiogenic shock: achieving more through less. Am Heart J 2013;165:256-7. 